\title{
Methylated and Trifluoromethylated Poly(aryl ethers)
}

\author{
Baijun LIU, ${ }^{*, * *}$ Wei Hu, ${ }^{*}$ Shuang ZHAO, ${ }^{*}$ Chunhai CHEN, ${ }^{*}$ Zhongwen Wu, \\ and Toshihiko MATSUMOTO ${ }^{\dagger, * *}$ \\ *Alan G. Macdiarmid Institute, Jilin University, Changchun 130023, P. R. China \\ ${ }^{* *}$ Center for Nano Science and Technology, Tokyo Polytechnic University, Atsugi, \\ Kanagawa 243-0297, Japan
}

(Received March 3, 2003; Accepted May 22, 2003)

\begin{abstract}
A series of poly(aryl ethers), derived from (3-methylphenyl)hydroquinone, (3-trifluoromethylphenyl)hydroquinone and (3,5-ditrifluoromethylphenyl)hydroquinone, were synthesized via a typical aromatic nucleophilic substitution reaction. The polycondensation quantitatively proceeded in the presence of anhydrous potassium carbonate to afford the polymers with an $\bar{M}_{\mathrm{n}}$ above 19000 . The glass transition temperatures of the polymers ranged from $143^{\circ} \mathrm{C}$ to $178^{\circ} \mathrm{C}$. The polymers showed high thermal decomposition temperatures, and the temperatures at which a $5 \%$ weight loss occurred were above $443^{\circ} \mathrm{C}$. Compared with the methylated polymers, the trifluoromethylated polymers exhibited a higher thermal stability. All the polymers showed good solubility due to the existence of pendant groups. Transparent and flexible thin polymer films could easily be obtained by solution casting. The dielectric constants of the polymers estimated from the refractive indices $\left(\varepsilon_{\mathrm{opt}}=1.1 n^{2}\right)$ were $2.45-2.96$. Because of the strong hydrophobicity of the fluorine-containing groups, the water uptakes of the polymers decreased with an increase in the fluorine-containing content.
\end{abstract}

KEY WORDS Fluorinated Polymers / Poly(aryl ethers) / Synthesis / Solubility / Dielectric Constant /

Poly(aryl ethers) consisting of aromatic rings and ether linkages represent an important class of high performance polymers because of their good mechanical, thermal, and electric properties. The existence of flexible ether linkages on the main chains is an efficient way to enhance the solubility and processability of aromatic polymers while minimizing changes in their physical properties. ${ }^{1,2}$ The introduction of cyano groups into the polymer chains may promote adhesion of the polymer to some substrates. Cyano groups could be transfered into other functional groups and serve as a potential site for polymer crosslinking. ${ }^{3}$

The continuing research efforts are made to meet the acute need for high-thermal materials for use in microelectric devices, such as the intermetal and interlayer dielectrics for integrated circuits, the substrates for printed circuit boards, and coatings in electronic packaging. ${ }^{4-6}$ The aromatic polymers with low dielectric constants, high thermal stability, good solubility, and low water uptakes have been widely explored. In general, introduction of fluorine-containing moieties and bulky pendant groups are regarded as good methods for polymers to obtain these properties. To meet the demands, the aromatic polymers with fluoro, trifluoro, adamantyl, and fluorenyl groups have been successfully prepared. ${ }^{7-11}$

Fluorinated polymers have been widely utilized for special applications because of their unique characteristics. Optical waveguides, microelectronic devices, low- energy surfaces, and gas-separation membrances are just a few uses among the various applications. In general, the incorporation of fluorinated substituents into the polymers will decrease the dielectric constants, optical loss, moisture absorption, and refractive indices while increasing the free volume, solubility, and thermal stability. Therefore, the hexafluoroisopropyl moieties are widely used in the synthesis of polyimides, polyethers, polyesters, polyamides, and other polymers. $^{12-18}$

We are interested in the preparation of the aromatic polymers with bulky fluorinated pendent groups. In this study, a series of poly(aryl ethers) derived from (3-methylphenyl)hydroquinone (m-TPH), (3-trifluoromethylphenyl)hydroquinone (3F$\mathrm{PH})$, and (3,5-ditrifluoromethylphenyl)hydroquinone (6F-PH), were prepared. The general properties of the poly(aryl ethers), such as thermal properties, solubility, water uptakes, and dielectric constants were investigated.

\section{EXPERIMENTAL}

\section{Materials}

(3-Methylphenyl)hydroquinone, (3-trifluoromethylphenyl)hydroquinone, and (3,5-ditrifluoromethylphenyl)hydroquinone were synthesized according to our previous paper. ${ }^{19}$ 2,6-Difluorobenzonitrile and perfluorobiphenyl were obtained from Tokyo Kasei Kogyo

${ }^{\dagger}$ To whom correspondence should be addressed (E-mail: matumoto@chem.t-kougei.ac.jp) 
Company. Tetramethylene sulfone (TMS, Jinzhou Oil Refinery) and $N, N$-dimethylacetamide(DMAc, Beijing Chemical Reagent) were purified by distillation under reduced pressure before use. Anhydrous potassium carbonate (Beijing Chemical Reagent) was ground into a fine powder and dried before use. All the other reagents were used as received.

\section{Measurements}

Fourier Transform Infrared (FT-IR) spectra of the thin polymer films were measured on a Nicolet Impact 410 FT-IR spectrometer. ${ }^{1} \mathrm{H}(500 \mathrm{MHz})$, and ${ }^{19} \mathrm{~F}(470.5 \mathrm{MHz})$ nuclear magnetic resonance (NMR) spectra were recorded on a Bruker 510 NMR spectrometer with tetramethyl silane $\left({ }^{1} \mathrm{H} \mathrm{NMR}\right)$ or $\mathrm{CFCl}_{3}$ $\left({ }^{19} \mathrm{~F}\right.$ NMR) as the reference. Gel permeation chromatograms (GPC) were obtained on a Waters 410 instrument with tetrahydrofuran (THF) as the eluent and polystyrene as the standard. The elemental analysis was carried out with a Thermoquest CHNS-O elemental analyzer. The wide-angle X-ray diffractometer (WAXD) patterns were measured on a Rigaku D/Max$\gamma \mathrm{A}$ X-ray diffractometer with graphite-monochromated $\mathrm{Cu}-K \alpha$ radiation. Differential scanning calorimetry (DSC) measurements were performed on a Mettler Toledo DSC $821^{\mathrm{e}}$ instrument at a heating rate of $20{ }^{\circ} \mathrm{C} \mathrm{min}^{-1}$ under nitrogen. A thermogravimetric analysis (TGA) was performed on a Netzch Sta 449 c thermal analyzer system at a heating rate of $20^{\circ} \mathrm{C} \mathrm{min}^{-1}$ in air. The refractive indices $\left(n_{\text {ref }}\right)$ of the polymer films (prepared by spin-coating of polymer chloroform solution) were obtained using a VASE M2000UI spectroscopic ellipsometer. The water uptakes of the polymers were measured by immersion of the polymer films $\left(5 \times 5 \times 0.5 \mathrm{~mm}^{3}\right.$, prepared by compression molding at $300^{\circ} \mathrm{C}$ ) in deionized water at $100^{\circ} \mathrm{C}$ for $2 \mathrm{~h}$, followed by wiping with tissue paper for removel of the water on the surface. The water uptakes were calculated from the difference in the weights before and after this procedure.

\section{SYNTHESIS OF POLYMERS}

\section{Poly(aryl ethers) with Cyano Groups (PEN)}

Ditrifluoromethylphenyl Substituted PEN (6F$P E N)$. 2,6-Difluorobenzonitrile $\quad(6.95 \mathrm{~g}, 50 \mathrm{mmol})$, 6F-PH (16.10 g, $50 \mathrm{mmol})$, anhydrous $\mathrm{K}_{2} \mathrm{CO}_{3}(8.97 \mathrm{~g}$, $65 \mathrm{mmol})$, TMS $(92 \mathrm{~mL})$ and toluene $(65 \mathrm{~mL})$ were placed in a $250 \mathrm{~mL}$ three-necked flask equipped with a mechanical stirrer, a nitrogen inlet, a Dean-Stark trap, and a condenser. The reaction mixture was allowed to reflux for $2 \mathrm{~h}$ under a nitrogen atmosphere. The toluene was removed by distillation, and then system was heated to $190^{\circ} \mathrm{C}$. The polymerization was complete after $4 \mathrm{~h}$. The viscous mixture was poured into $1000 \mathrm{~mL}$ of deionized water. The threadlike polymer was pulverized into a fine powder by a blender. The powder was washed several times with hot methanol and water. The white polymer powder was obtained after drying at $120^{\circ} \mathrm{C}$ for $24 \mathrm{~h}$.

Yield: $87 \%$.

FT-IR (film, $\left.\mathrm{cm}^{-1}\right): 2232(-\mathrm{C} \equiv \mathrm{N}), 1242(\mathrm{Ar}-\mathrm{O}-\mathrm{Ar})$, $1135\left(-\mathrm{CF}_{3}\right)$.

${ }^{1} \mathrm{H} \mathrm{NMR}\left(\mathrm{CDCl}_{3}, \mathrm{ppm}\right): \delta 8.03-7.84(\mathrm{~m}, 3 \mathrm{H}), 7.35-$ 7.15 (m, $4 \mathrm{H}), 6.69-6.40$ (m, $2 \mathrm{H})$.

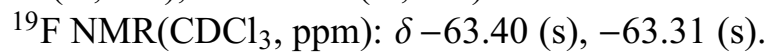

$\left(\mathrm{C}_{21} \mathrm{H}_{9} \mathrm{~F}_{6} \mathrm{~N}_{1} \mathrm{O}_{2}\right)_{n}(421.29)_{n}$ : Calcd. C, 59.87; H, 2.15; Found C, 60.18; H, 2.12.

Trifluoromethylphenyl Substituted PEN (3F-PEN) and Methylphenyl Substituted PEN (m-TPEN). 3FPEN and $\mathrm{m}$-TPEN were prepared by the polymerization of 1 equiv. of 2,6-difluorobenzonitrile with 3F-PH and $\mathrm{m}-\mathrm{TPH}$, respectively, according to the same procedure used for 6F-PEN.

3F-PEN. Yield: $85 \%$. FT-IR (film, $\mathrm{cm}^{-1}$ ): 2230 $(-\mathrm{C} \equiv \mathrm{N}), 1242(\mathrm{Ar}-\mathrm{O}-\mathrm{Ar}), 1126\left(-\mathrm{CF}_{3}\right)$.

${ }^{1} \mathrm{H}$ NMR $\left(\mathrm{CDCl}_{3}, \mathrm{ppm}\right): \delta 7.79-7.51(\mathrm{~m}, 4 \mathrm{H}), 7.31-$ $7.11(\mathrm{~m}, 4 \mathrm{H}), 6.52-6.12(\mathrm{~m}, 2 \mathrm{H})$.

${ }^{19} \mathrm{~F} \mathrm{NMR}\left(\mathrm{CDCl}_{3}, \mathrm{ppm}\right): \delta-63.08(\mathrm{~s})$.

$\left(\mathrm{C}_{20} \mathrm{H}_{10} \mathrm{~F}_{3} \mathrm{~N}_{1} \mathrm{O}_{2}\right)_{n}(353.29)_{n}$ : Calcd. C, 67.99; H, 2.85; Found C, 67.71; H, 2.79.

m-TPEN. Yield: $88 \%$. FT-IR (film, $\left.\mathrm{cm}^{-1}\right): 2229$ $(-\mathrm{C} \equiv \mathrm{N}), 1241(\mathrm{Ar}-\mathrm{O}-\mathrm{Ar})$.

${ }^{1} \mathrm{H} \mathrm{NMR}\left(\mathrm{CDCl}_{3}, \mathrm{ppm}\right): \delta 7.42-6.99(\mathrm{~m}, 8 \mathrm{H}), 6.62-$ $6.16(\mathrm{~m}, 2 \mathrm{H}), 2.36(\mathrm{~s}, 3 \mathrm{H})$.

$\left(\mathrm{C}_{20} \mathrm{H}_{13} \mathrm{~N}_{1} \mathrm{O}_{2}\right)_{n}(299.32)_{n}$ : Calcd. C, 80.25; H, 4.38; Found C, 79.81; H, 4.40 .

\section{Poly(aryl ethers) with Perfluorobiphenyl Groups (PAE)}

Ditrifluoromethylphenyl Substituted PAE (14F-PAE). Into a $250 \mathrm{~mL}$ three-necked flask equipped with a magnetic stirrer, a nitrogen inlet, a Dean-Stark trap, and a condenser was added $6 \mathrm{~F}-\mathrm{PH}(3.22 \mathrm{~g}, 10 \mathrm{mmol})$, anhydrous $\mathrm{K}_{2} \mathrm{CO}_{3}(2.76 \mathrm{~g}, 20 \mathrm{mmol})$, DMAc $(35 \mathrm{~mL})$ and toluene $(65 \mathrm{~mL})$ under a nitrogen atmosphere. The reaction mixture was heated to reflux and kept for $5 \mathrm{~h}$. The mixture was cooled to room temperature after removal of the toluene. A $3.34 \mathrm{~g}(10 \mathrm{mmol})$ amount of perfluorobiphenyl was added to the reaction mixture. The solution was stirred at room temperature for $72 \mathrm{~h}$. The viscous mixture was poured into a mixture of methanol and water (50/50, volume ratio). The polymer was washed with hot methanol and water, then dried at $120^{\circ} \mathrm{C}$ for $24 \mathrm{~h}$.

Yield: $83 \%$.

FT-IR (film, $\left.\mathrm{cm}^{-1}\right)$ : 1250 (Ar-O-Ar), $1138\left(-\mathrm{CF}_{3}\right)$, 


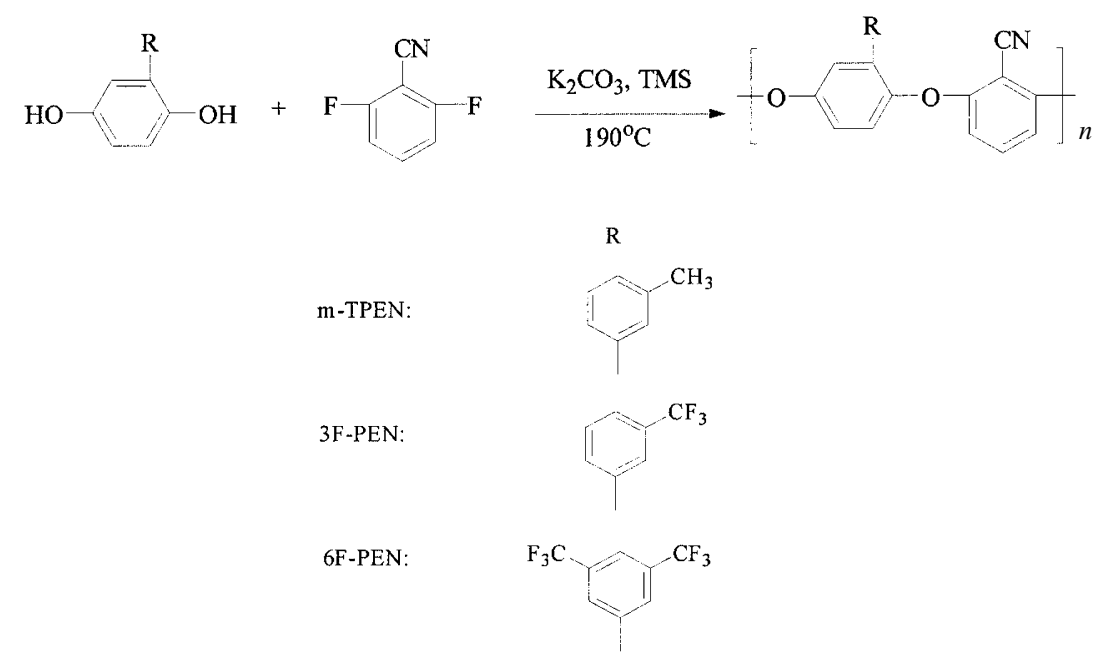

Scheme 1. Synthesis of poly(aryl ethers) with cyano groups.

1074 (Ar-F).

${ }^{1} \mathrm{H} \mathrm{NMR}\left(\mathrm{CDCl}_{3}, \mathrm{ppm}\right): \delta 8.04(\mathrm{~s}, 2 \mathrm{H}), 7.91(\mathrm{~s}, 1 \mathrm{H})$, $7.20(\mathrm{~s}, 1 \mathrm{H}), 7.05(\mathrm{~d}, J=8.4 \mathrm{~Hz}, 1 \mathrm{H}), 6.97(\mathrm{~d}, J=$ $8.4 \mathrm{~Hz}, 1 \mathrm{H}) .{ }^{19} \mathrm{~F} \mathrm{NMR}\left(\mathrm{CDCl}_{3}, \mathrm{ppm}\right): \delta-63.34(\mathrm{~s}, 6 \mathrm{~F})$, -137.73 (s, 4F), -153.06 -153.62 (m, 4F).

$\left(\mathrm{C}_{26} \mathrm{H}_{6} \mathrm{~F}_{14} \mathrm{O}_{2}\right)_{n}(616.30)_{n}$ : Calcd. C, 50.67; H, 0.98; Found C, 50.10, H, 0.98 .

Trifluoromethylphenyl Substituted PAE (11F-PAE) and Methylphenyl Substituted PAE (8F-PAE). 11FPAE and $8 \mathrm{~F}-\mathrm{PAE}$ were prepared by the polymerization of 1 equiv. of perfluorobiphenyl with 3F-PH and $\mathrm{m}$-TPH, respectively, according to the same procedure used for 14F-PAE.

11F-PAE. Yield: 90\%. FT-IR (film, $\mathrm{cm}^{-1}$ ): 1252 (Ar-O-Ar), $1130\left(-\mathrm{CF}_{3}\right), 1074$ (Ar-F).

${ }^{1} \mathrm{H}$ NMR $\left(\mathrm{CDCl}_{3}, \mathrm{ppm}\right): \delta 7.83(\mathrm{~s}, 1 \mathrm{H}), 7.75(\mathrm{~d}$, $J=7.2 \mathrm{~Hz}, 1 \mathrm{H}), 7.64(\mathrm{~d}, J=7.6 \mathrm{~Hz}, 1 \mathrm{H}), 7.55(\mathrm{t}$, $\left.J_{1}=8.0 \mathrm{~Hz}, J_{2}=7.2 \mathrm{~Hz}, 1 \mathrm{H}\right), 7.16(\mathrm{~s}, 1 \mathrm{H}), 7.94(\mathrm{~d}$, $J=8.8 \mathrm{~Hz}, 1 \mathrm{H}), 6.97(\mathrm{~d}, J=8.8 \mathrm{~Hz}, 1 \mathrm{H}) .{ }^{19} \mathrm{~F} \mathrm{NMR}$ $\left(\mathrm{CDCl}_{3}, \mathrm{ppm}\right): \delta-63.15(\mathrm{~s}, 3 \mathrm{~F}),-137.84 \sim-138.35$ (m, 4F), $-153.17 \sim-153.87(\mathrm{~m}, 4 \mathrm{~F})$.

$\left(\mathrm{C}_{25} \mathrm{H}_{7} \mathrm{~F}_{11} \mathrm{O}_{2}\right)_{n}(548.30)_{n}$ : Calcd. C, 54.76; H, 1.29; Found C, $54.28 \mathrm{H}, 1.30$.

8F-PAE.Yield: 84\%. FT-IR (film, $\mathrm{cm}^{-1}$ ): $1249(\mathrm{Ar}-$ O-Ar), 1074 (Ar-F).

${ }^{1} \mathrm{H}$ NMR $\left(\mathrm{CDCl}_{3}, \mathrm{ppm}\right): \delta 7.34-7.27(\mathrm{~m}, 3 \mathrm{H}), 7.17$ $(\mathrm{d}, J=6.4 \mathrm{~Hz}, 1 \mathrm{H}), 7.10(\mathrm{~s}, 1 \mathrm{H}), 7.06-6.97(\mathrm{~m}, 2 \mathrm{H})$, 2.39 (s, $3 \mathrm{H}) .{ }^{19} \mathrm{~F}$ NMR $\left(\mathrm{CDCl}_{3}, \mathrm{ppm}\right): \delta-138.03 \sim$ $-139.10(\mathrm{~m}, 4 \mathrm{~F})-153.29 \sim-154.12(\mathrm{~m}, 4 \mathrm{~F})$.

$\left(\mathrm{C}_{25} \mathrm{H}_{10} \mathrm{~F}_{8} \mathrm{O}_{2}\right)_{n}(494.33)_{n}$ : Calcd. C, 60.74; H, 2.04; Found C, 60.27; H.1.96.

\section{RESULTS AND DISCUSSION}

Synthesis of Polymers

The nucleophilic aromatic substitution polymeriza-

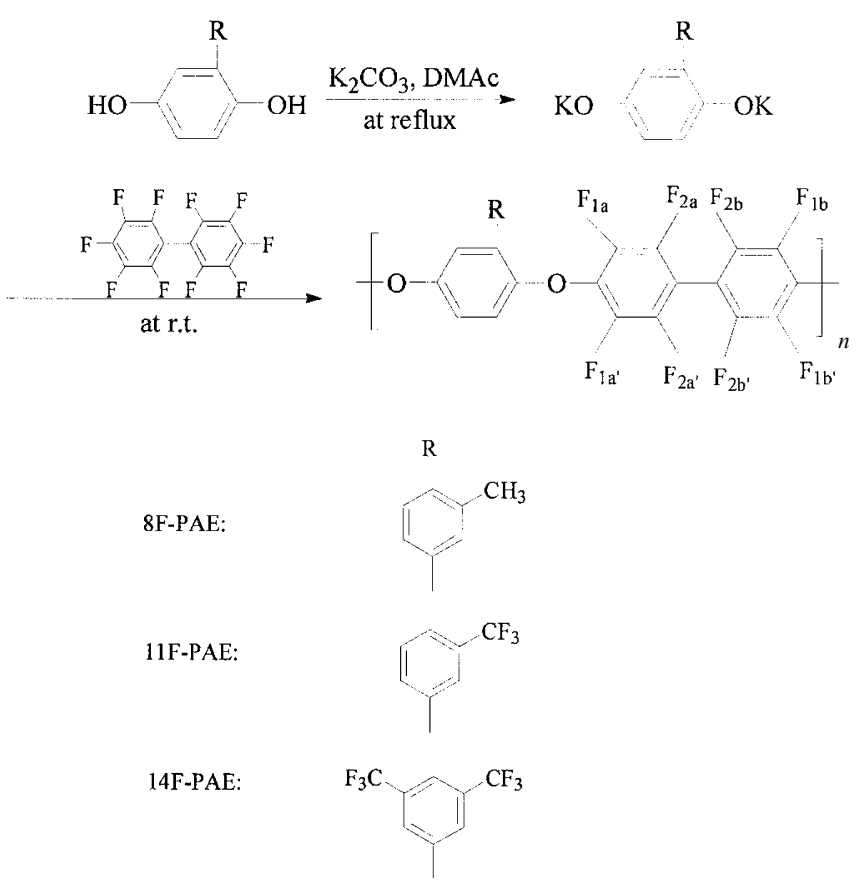

Scheme 2. Synthesis of poly(aryl ethers) with perfluorobiphenyl groups.

tion of three novel hydroquinone derivatives with two activated fluoro monomers was carried out in the presence of excess anhydrous $\mathrm{K}_{2} \mathrm{CO}_{3}$ as a base. The toluene was used for the azeotropic removal of water generated from the deprotonation of hydroquinones. Because the number of reactive fluorine atoms in perfluorobiphenyl is greater than two, a different reaction route was used. In the reaction of the hydroquinones with 2,6-difluorobenzonitrile (Scheme 1), the monomers were fed at the same time. After the completion of the hydroquinone dianion formation, the reaction temperature was elevated to $190^{\circ} \mathrm{C}$. However, to avoid the occurrence of a cross-linking reaction, the two-step route (Scheme 2) was performed in the case of 
Table I. GPC data of the poly(aryl ethers) ${ }^{\text {a }}$

\begin{tabular}{lcc}
\hline Polymer & $\bar{M}_{\mathrm{n}}$ & Polydispersity $\left(\bar{M}_{\mathrm{w}} \bar{M}_{\mathrm{n}}\right)$ \\
\hline m-TPEN & 46000 & 2.91 \\
3F-PEN & 37000 & 3.07 \\
6F-PEN & 41000 & 2.73 \\
8F-PAE & 19000 & 1.74 \\
11F-PAE & 29000 & 2.34 \\
14F-PAE & 21000 & 1.78 \\
\hline \multicolumn{2}{c}{ aMeasured by GPC in THF; polystyrene was used as } \\
standard.
\end{tabular}

perfluorobiphenyl. ${ }^{20}$ After the completion of the dianion formation, the reaction system was cooled to room temperature, and then the fluoro monomer was added. To obtain the high molecular weight polymers, a long polymerization period was needed. The number average weight $\left(\bar{M}_{\mathrm{n}}\right)$ and polydispersity $\left(\bar{M}_{\mathrm{w}} / \bar{M}_{\mathrm{n}}\right)$ of all the resulting polymers are listed in Table I. The GPC measurements demonstrated that the polymers exhibited $\bar{M}_{\mathrm{n}}$ and $\bar{M}_{\mathrm{w}} \bar{M}_{\mathrm{n}}$ in the range of $19000-46000$ and $1.74-3.07$, respectively.

The FT-IR spectra of the polymers support their structures. All the polymers exhibited the characteristic absorption bands in the range of $1241-1252 \mathrm{~cm}^{-1}$ due to the aryl ether linkages. The characteristic absorption band around $1130 \mathrm{~cm}^{-1}$ corresponding to the trifluoromethyl group was observed in the spectra of all the trifluoromethylated polymers. In addition, the 2,6-difluorobenzonitrile based polymers showed the characteristic absorption peaks around $2230 \mathrm{~cm}^{-1}$ due to the cyano moiety, and the polymers derived from the perfluorobiphenyl exhibited absorption bands at $1074 \mathrm{~cm}^{-1}$ due to the aryl fluorine linkage.

In the ${ }^{1} \mathrm{H}$ NMR and ${ }^{19} \mathrm{~F}$ NMR spectra of the polymers, the assignments of the peaks were in good agreement with the proposed structure. The signals ranging from 6.12 to $8.04 \mathrm{ppm}$ in the ${ }^{1} \mathrm{H}$ NMR were assigned to the aromatic protons of the polymer chains. The characteristic peaks of the methyl groups of mTPEN and 8F-PAE appeared at 2.36 and $2.39 \mathrm{ppm}$, respectively. In the ${ }^{19} \mathrm{~F}$ NMR spectra of 6F-PEN, 3FPEN, 14F-PAE and 11F-PAE (Figure 1), the absorption peaks of the trifluoromethyl groups were observed at about $-63 \mathrm{ppm}$. The ${ }^{19} \mathrm{~F}$ NMR spectra of $14 \mathrm{~F}-$ PAE and 11F-PAE showed three groups of peaks corresponding to the three kinds of distinguishable fluorines. However, only two groups of peaks centered at -138.5 and $-153.8 \mathrm{ppm}$ corresponding to the fluorines of biphenyls in the ${ }^{19} \mathrm{~F}$ NMR spectrum of $8 \mathrm{~F}-\mathrm{PAE} .{ }^{10} \mathrm{As}$ expected, due to the existence of asymmetric moieties in the backbones, the chemical shifts for fluorines of biphenyls exhibited a little difference. It could be observed in the enlarged absorption regions in the spec- a). $14 \mathrm{~F}-\mathrm{PAE}$

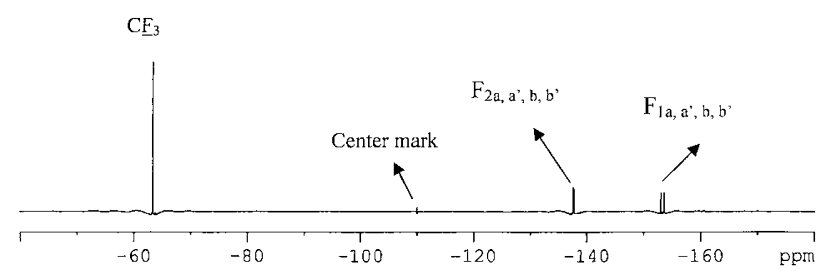

b). 8 F-PAE

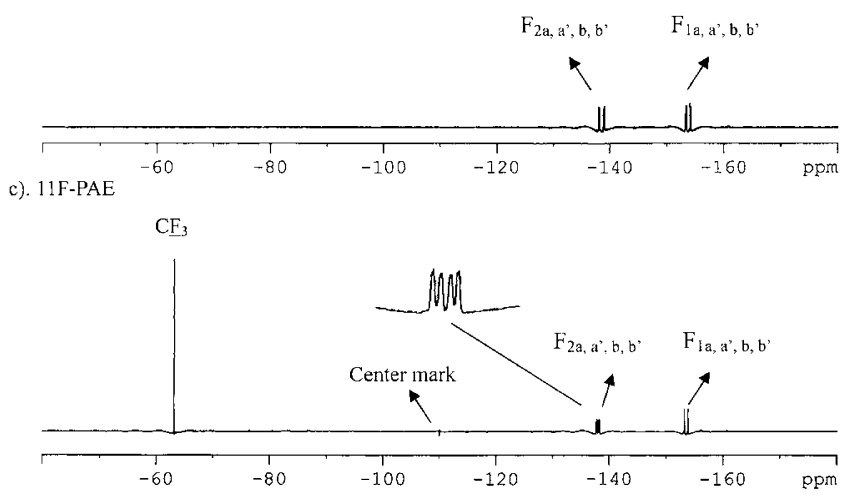

Figure 1. ${ }^{19} \mathrm{~F}$ NMR spectra of $8 \mathrm{~F}-\mathrm{PAE}, 11 \mathrm{~F}-\mathrm{PAE}$, and $14 \mathrm{~F}-$ PAE.

Table II. Thermal properties of the poly(aryl ethers) ${ }^{\mathrm{a}}$

\begin{tabular}{lccc}
\hline Polymer & $T_{\mathrm{g}}\left({ }^{\circ} \mathrm{C}\right)^{\mathrm{b}}$ & $D T_{5}\left({ }^{\circ} \mathrm{C}\right)^{\mathrm{c}}$ & $D T_{10}\left({ }^{\circ} \mathrm{C}\right)^{\mathrm{d}}$ \\
\hline m-TPEN & 170 & 443 & 496 \\
3F-PEN & 154 & 510 & 537 \\
6F-PEN & 178 & 525 & 563 \\
8F-PAE & 147 & 466 & 507 \\
11F-PAE & 143 & 535 & 549 \\
14F-PAE & 152 & 539 & 553 \\
\hline
\end{tabular}

${ }^{\mathrm{a}}$ The polymer powder was used. ${ }^{\mathrm{b}}$ From the second heating trace of DSC measurements conducted at a heating rate of $20^{\circ} \mathrm{Cmin}^{-1}$. ${ }^{\mathrm{c}} 5 \%$ weight loss temperatures measured by TGA at a heating rate of $20^{\circ} \mathrm{C} \mathrm{min}^{-1}$. ${ }^{\mathrm{d}} 10 \%$ weight loss temperatures measured by TGA at a heating rate of $20^{\circ} \mathrm{C} \mathrm{min}^{-1}$.

tra of 8F-PAE and 11F-PAE. However, the difference is not obvious in the spectrum of 14F-PAE, which could be explained by the introduction of the symmetric 3,5ditrifluoromethylphenyl groups.

The crystallinity of the polymers was examined by WAXD. All the polymers showed amorphous patterns. The results were in agreement with the structure of the polymers. The existence of the bulky pendant groups disrupted the regularity of the molecular chains and inhibited the close packing of the polymer chains.

\section{Thermal Properties and Solubility of Polymers}

DSC and TGA were used to evaluate the thermal properties of the polymers, and these results are summarized in Table II. All the poly(aryl ethers) exhibited no crystallization or melting transition in their DSC curves, which confirmed their amorphous morphology. 
The $T_{\mathrm{g}} \mathrm{S}$ of the polymers ranged from $143^{\circ} \mathrm{C}$ to $178^{\circ} \mathrm{C}$. Compared with polymers with 3-methylphenyl and 3trifluoromethylphenyl side groups, the polymers with the 3,5-ditrifluoromethylphenyl side groups showed higher $T_{\mathrm{g}} \mathrm{s}$. The bigger pendent groups due to the introduction of two trifluoromethyl groups will raise the $T_{\mathrm{g}}$ in spite of the other factors. A possible explanation for the lower $T_{\mathrm{g}} \mathrm{s}$ of 3-trifluoromethylphenyl polymers is that the substitution of methyl with trifluoromethyl would lead to an internal plasticization in addition to the geometry and free-volume factors. . $^{19,21}$

The poly(aryl ethers) showed good thermal stability based on their aromatic molecular structure. The temperatures at a $5 \%$ weight loss $\left(T D_{5}\right)$ and at a $10 \%$ weight loss $\left(T D_{10}\right)$ in air were above $443^{\circ} \mathrm{C}$ and $496^{\circ} \mathrm{C}$, respectively. As anticipated, the trifluoromethylated polymers had a higher thermal stability than the methylated polymers, which is attributed to the stronger $\mathrm{C}-\mathrm{F}$ bonds in comparison with the $\mathrm{C}-\mathrm{H}$ bonds.

All the polymers were soluble at room temperature in aprotic polar solvents such as NMP, DMAc, and DMF as well as in the less polar solvents such as chloroform and tetrahydrofuran (THF). The good solubility of the poly(aryl ethers) was attributed to the combined effects of the pendent groups such as the methylated or trifluoromethylated benzene ring, the cyanos and fluorines, and flexible ether linkages in the polymer backbone. The transparent and flexible thin films could be easily obtained by solution casting.

\section{Dielectric Constants and Water Uptakes of Polymers}

The dielectric constants of the polymer films were estimated from the refractive indices at $632.8 \mathrm{~nm}$ according to the modified Maxwell equation $\left(\varepsilon_{\mathrm{opt}}=1.1\right.$ $\left.n^{2}\right) .{ }^{22}$ All the polymers had dielectric constants in the range of 2.96-2.45 (Table III). The lower dielectric constants would be attributed to the existence of the fluorine atoms and the bulky pendent groups. The dielectric constants of the PEN and PAE polymers decreased with the change in the side groups in the or-

Table III. Dielectric constants and water absorption of polymers

\begin{tabular}{lcc}
\hline Polymer & $\begin{array}{c}\text { Dielectric constant } \\
\left(\varepsilon_{\text {opt }}\right)\end{array}$ & $\begin{array}{c}\text { Water absorption }^{\mathrm{b}} \\
(\%)\end{array}$ \\
\hline m-TPEN & 2.96 & 0.57 \\
3F-PEN & 2.91 & 0.51 \\
6F-PEN & 2.65 & 0.46 \\
8F-PAE & 2.79 & 0.22 \\
11F-PAE & 2.70 & 0.20 \\
14F-PAE & 2.45 & 0.15 \\
\hline
\end{tabular}

${ }^{\mathrm{a}}$ Optically estimated, $\varepsilon=1.1 n^{2}$. ${ }^{\mathrm{b}}$ Calculated from the difference in the weights before and after immersion of the polymer films in water. der: $\mathrm{m}$-TPEN $>3$ F-PEN $>6$ F-PEN and 8F-PAE $>11 \mathrm{~F}-$ PAE $>14 \mathrm{~F}-\mathrm{PAE}$, respectively. In addition, the dielectric constant of the PAE polymer was lower than that of the corresponding PEN polymer. Both of the results could be explained by the introduction of fluorinated moieties, which would efficiently decrease the dielectric constants.

The water uptakes of the polymer films were in the range of $0.57-0.15 \%$ (Table III). Compared with the corresponding PEN polymers, the PAE polymers showed lower water uptakes because of the substitution of a cyanophenyl moiety by the perfluorobiphenyl one. The water uptakes of the poly(aryl ethers) decreased with the increase in the fluorine contents. These results were due to the strong hydrophobicity of the fluorinated moieties.

\section{CONCLUSIONS}

A series of methylphenyl, trifluoromethylphenyl, and ditrifluoromethylphenyl substituted poly(aryl ethers) have been successfully synthesized. All the polymers showed a high thermal stability, and their $T D_{5}$ and $T D_{10}$ values were above $443{ }^{\circ} \mathrm{C}$ and $496^{\circ} \mathrm{C}$, respectively. They were soluble in NMP, DMAc, DMF, chloroform, and THF at room temperature, and flexible and transparent thin films could be obtained by solution casting. The dielectric constants of the polymer films were in the range of 2.96-2.45. The fluorinated polymers possessed lower water uptakes, and the water uptake decreased with an increase in the fluorine content. The poly(aryl ethers) may be potential candidates as a low dielectric constant material, and other coating applications.

Acknowledgment. The authors thank the Chinese High Technology and Development Program and Japanese Academic Frontier Program for the financial support.

\section{REFERENCES}

1. R. J. Cotter, "Engineering Plastics: A Handbook of Polyarylethers", Golden and Breach Publishers, Amsterdam, 1995.

2. A. A. Goodwin, F. W. Mercer, and M. T. McKenzie, Macromolecules, 30, 2767 (1997).

3. V. L. Rao, A. Saxena, and K. N. Ninan J. Macromol. Sci., Polym. Rev., C42, 513 (2002).

4. P. E. Cassidy, T. M. Aminabhavi, and J. M. Farley, J. Macromol. Sci., Rev. Macromol. Chem. Phys., 29, 365 (1989).

5. M. L. Minges, "Electronic Materials Handbook", ASM International, Materials Park, OH, 1989.

6. G. Maier, Prog. Polym. Sci., 26, 3 (2001). 
7. S. H. Hsiao and C. T. Lee, J. Polym. Sci., Part A: Polym. Chem., 37, 1403 (1999).

8. H. Seino, A. Mochizuki, and M. Ueda, J. Polym. Sci., Part A: Polym. Chem., 37, 3584 (1999).

9. T. Takasaki, Y. Kuwana, T. Takahashi, and S. Hayashida, J. Polym. Sci., Part A: Polym. Chem., 38, 4832 (2000).

10. F. Mercer, T. Goodman, J. Wojtowicz, and D. J. Duff, J. Polym. Sci., Part A: Polym. Chem., 30, 1767 (1992).

11. H. Zhou, J. Liu, Z. Qian, S. Zhang, and S. Yang, J. Polym. Sci., Part A: Polym. Chem., 39, 2404 (2001).

12. H. Lee, E. Lee, M. Lee, M. Oh, J. Ahn, S. Han, and H. Kim, J. Polym. Sci., Part A: Polym. Chem., 36, 2881 (1998).

13. M. Kakimoto, S. Harada, Y. Oishi, and Y. Imai, J. Polym. Sci., Polym. Chem. Ed., 25, 2747 (1987).

14. B. Silverman, P. Sanda, P. Ho, and A. Rossi, J. Polym. Sci., Polym. Chem. Ed., 23, 2857 (1985).

15. L. Tan and F. Arnold, J. Polym. Sci., Polym. Chem. Ed., 25, 3159 (1987).
16. S. Ando, T. Matsuura, and S. Sasaki, Macromolecules, 25, 5858 (1992).

17. F. Liu, J. Ding, M. Li, M. Day, G. Robertson, and M. Zhou, Macromol. Rapid Commun., 23, 844 (2002).

18. S. Banerjee and G. Maier, Chem. Mater., 11, 2179 (1999).

19. B. J. Liu, G. B. Wang, W. Hu, Y. H. Jin, C. H. Chen, Z. H. Jiang, W. J. Zhang, Z. W. Wu, and Y. Wei, J. Polym. Sci., Part A: Polym. Chem., 40, 3392 (2002).

20. J. A. Irvin, C. J. Neef, K. M. Kane, P. E. Cassidy, G. Tullos, and A. K. St. Clair, J. Polym. Sci., Part A: Polym. Chem., 30, 1675 (1992).

21. G. Hougham, G. Tesoro, A. Viehbeck, and J. Chapple-Sokol, Macromolecules, 27, 5964 (1994).

22. T. Matsumoto, "Advances in Low-k Dielectrics And Thermally Stable Polymers for Microelectronics", Society of Plastics Engineers, Mid Hudson Section, New York, N.Y., 2002, p 121. 